\title{
The Economic Impact of Sporting Events in Lane County
}

\author{
David Cole, John Hurley, and Jeffrey Naber, Economics*
}

\begin{abstract}
When considering the full economic impact of sports in Lane County, the first events that come to mind involve the University of Oregon athletics program. But the Ducks are not the only events that the University hosts. For example, Hayward Field is the home of the yearly Prefontaine Classic. State high school football championships take place in Autzen Stadium, along with the Susan G. Komen Race for the Cure. The Matthew Knight Arena hosts championships for high school basketball, along with the Duck's basketball program. Moreover, the University is not the only place in Lane County that holds these events. The Willamalane Center for Sports and Recreation hosts state volleyball championships, gymnastic meets, and even roller derby. There are drag boat races at Dexter State Recreation Park, sailing regattas at Fern Ridge Reservoir, marathons, golf, model airplane, and horsing events held in town. Amazon Pool hosts several swim meets every summer, each with hundreds of athletes and spectators. Understanding the full impact of sporting events on Lane County's economy requires understanding how varied the sporting culture is in the county.
\end{abstract}

\section{INTRODUCTION}

The purpose of the report is to estimate the impact of sporting events on the Lane County economy during 2013. Over 200,000 people attended sporting events hosted in Lane County in 2013, and their spending produced a sizable impact on the local economy:

- Between \$31.6 and \$43.1 million in additional economic output;

\footnotetext{
*David Cole was born and raised in Portland Oregon. He graduated from the University of Oregon in the spring of 2014 with an honors degree in Economics. After graduation he accepted a position as a logistics specialist at Colombia Brewing Co. When he isn't working he enjoys mastering the art of crochet and dance.

*John Hurley grew up in Dallas Oregon. He will graduate from the University of Oregon in 2015 with a double degree in Economics and Accounting. He is active in the University of Oregon Investment Group and a founder of the University of Oregon Economics Club. After graduation he plans on working in investment banking or economic research. In his free time John enjoys playing music, reading, and spending time with friends and family.

*Jeffrey Naber is originally from Nebraska. He moved to Oregon in 2007, and graduated with honors from Portland Community College before transferring to the University of Oregon in 2012. During his time at the UO, he majored in Economics and Applied Mathematics, and helped to found the UO Economics Club, serving as its first President. After graduating with departmental honors in the Summer of 2014, he accepted a position as a research assistant with the Board of Governors of the Federal Reserve System, and currently resides in Washington, D.C.
} 
- Between \$9.6 and \$13.1 million additional earnings for employees in Lane County;

- Between 386 and 512 additional jobs created to support these spectators' spending.

In addition, events hosted by Junction City Athletics and Lane Community College accounted for an estimated:

- $\quad \$ 10.4$ million in economic output;

- $\quad \$ 3.1$ million in earnings for local workers;

- 127 additional jobs in 2013.

This substantial impact to the economy would not be possible without the diverse sporting community, both collegiate and community that exists within Lane County.

\section{LITERATURE REVIEW}

The economic impact of sporting events is a well-studied area. For this project, we focused our research on studies that closely matched the demographics of Eugene and Lane County, notably avoiding the economic impact of professional sports, as there are substantial differences between local level, collegiate, and professional sporting events. The purpose of avoiding professional sporting events is to keep the analysis an apples-to-apples comparison: professional sports teams have significantly different cost and revenue structures, as well as differing supply chains.

A common thread across every study reviewed was the importance of differentiating between spending by local spectators and out-of-town spectators. Local spectators, had they not visited a sporting event, would have likely spent the money on some other form of local recreation. In other words, if an event does not provide for a new source of spending in the community that is directly related to that event, then that event has no economic impact (Duy). The spending in the local economy would likely have occurred with or without the sporting event. This demonstrates why it is important to pay attention to the origin of the spectators and athletes when measuring the true economic impact. Every study considered took this effect into account and made specific note of the impact to the local economy from out-of-town visitors, a methodology followed in this paper.

All of the studies researched defined the total impact of sporting events as the combination of both the direct, indirect, and induced impacts of the events. The direct impact captures the initial payments made by the venue to its employees and local businesses to provide the services (personnel, maintenance, signage, and so on) necessary to run the venue. Direct spending also captures additional expenditures by visitors, such as meals, hotel rooms, and any other such spending that takes place in association with attending the sporting event. The indirect and induced effects are explained through the use of economic multipliers. 
Multipliers are built around the fact that expenditure from one economic agent is income for a second agent. The second agent then spends a portion of that new income, which becomes income for another agent and so on. This allows each dollar spent to have a greater economic impact than \$1. Direct effects take into account the spending of revenues by local vendors. For example, a family in town for a volleyball tournament might stop at a local restaurant for dinner before leaving for home. That local restaurant then spends that new revenue on local vendors for supplies, which then has a second impact on the local economy. Induced effects take into account further spending by local employees. The server at the restaurant now has additional income they would not have gained, had the family not come into town. The server now uses that income to purchase goods and services in the local economy providing a secondary impact.

The framework of this study's methodology encompasses the use of economic multipliers derived from the RIMS II regional economic model provided by the Bureau of Economic Analysis (BEA). The RIMS II model was created as a tool for investors, planners, and elected officials to estimate potential economic impacts of public or private projects. The model uses economic multipliers appropriate to the project and the region the project is being conducted in. The RIMS II framework is based on a set of national input-output accounts that show the goods and services produced by each industry and final users. These input-output accounts provide the foundation for the model's economic multipliers. The benefit and the limitation of using RIMS II multipliers is that these multipliers are only meaningful for analyzing the impact of a final demand change in a region. These final demand transactions take the form of 1) purchases by consumers outside the region, 2) investment in new building, equipment, and software, 3) purchases by government, and 4) purchases by households. These transactions are considered final because they are not used as intermediate inputs by industries in the region. However, as is the case with all economic models, there are certain assumptions that must be made and recognized while conducting the economic impact study. The RIMS II model assumptions implemented in this study are detailed in appendix $\mathrm{A}$

Multipliers are widely used throughout economic impact studies. For this paper we are making use of the RIMS II (Regional Input/Output Modeling System) provided by the BEA. The RIMS II multipliers do not have separate multipliers for induced effects. However, this is not a concern with this paper, as we are considering only the impact from out-of-town visitors. These multipliers break out the multiplier effect by industry to better explain how sporting events affect the community. The RIMS II multipliers are region-specific, providing estimators unique to Lane County. The studies examined had multipliers ranging from 1.5 (Thompson) to 1.81 (University of Arkansas) for expenditures. The multipliers used in this paper are all within this range, suggesting this methodology is within an acceptable range.

These multipliers were applied to estimated values of spending both from day and overnight attendees. The studies we reviewed also provided a range of possible estimates. Travel Lane County estimates that overnight visitors spend an average of $\$ 166$ per day, while day visitors spend \$57 per day. A study done for Traverse City, Michigan, examined the spending effects of out-of-town visitors attending multi-day youth soccer tournaments and found average total spending per family to be $\$ 518.42 /$ day for visitors to the annual Cherry Cup youth soccer 
tournament, and $\$ 410.42 /$ day to the annual Cherry Bomb youth lacrosse tournament (Smith). Discrepancies between these estimates are due in large part because of a mandatory fee charged to the Traverse City study participants.

The Traverse City, Michigan study provides examples of other important issues to consider with an economic impact study. The authors began by mentioning an estimation made by the Sporting Goods Manufacturers Association (SGMA), stating that nearly 70\% of children between the ages 6-17 in the U.S. are participating in at least one team sport. The authors state that there has been a large increase in the number of traveling teams to away games and tournaments. These youth tournaments are often 2-3 days long and are played by multiple teams traveling from all over the country. According to Don Schumacher of the National Association of Sports Commissions, parents spent about $\$ 7$ billion in 2012, on just traveling involved with youth sports. The researchers examined the economic impact of the Cherry Capital Cup youth soccer tournament and the Cherry Bomb youth lacrosse tournament on the local economy of Traverse City. The researchers conducted several interviews with the tournament hosts and sent out hundreds of surveys to the tournament participants to get a thorough understanding of the participant demographics and spending habits. The researchers recognized that since these are youth tournaments, most players are accompanied by at least one parent. The researchers found that $66 \%$ of the athletes had two parents with them, $50 \%$ had one or more siblings, $16 \%$ have one or more grandparents, and $14 \%$ have additional relatives joining them. The researchers' surveys revealed that each athlete competing in the tournaments had brought 2.14 additional people with them. Combined, the weekend tournaments attracted 17,400 people, $80 \%$ of which had traveled from outside the Traverse City area to take part in the tournament. Drawing on the results of the survey, the study estimates an average total spending of $\$ 985$ per non-local family attending either tournament, resulting in $\$ 3.4$ million in direct spending in the region. It is noteworthy that the researchers specifically chose to not use an economic multiplier to estimate indirect spending, as there was debate as to which multiplier to use.

The authors did note that their estimates were conservative, and that the use of an economic multiplier could in fact help get an estimate of the tournament's indirect impact in the regional economy-- noting that most studies use a multiplier of 1.3. The use of multipliers in determining economic impacts is widely accepted and used in economic research. A study conducted in Charlotte, NC MSA economy in 2011 employed economic multipliers when analyzing the economic impacts of sporting events in the region. The primary focus of the study was on the more important measure of economic activity concerning output and employment. To determine the total economic impact on output and employment due to sporting events, the study used the multiplier methodology IMPLAN provided by the Minnesota IMPLAN Group. Originally developed by the U.S. government, IMPLAN provides industry-specific multipliers, as does the BEA's RIMS II multipliers. The indirect multipliers obtained from IMPLAN were used to determine the overall economic impact in sectors including spectator sports, radio and television broadcasting, cable networks and program distribution, food and beverage stores, gasoline stations, general merchandise stores, hotels and motels, and food services and drinking places. The study first determined the direct impact in these industries in association with expenditures that took place with the event. After the direct impact was determined, the IMPLAN multipliers 
were used on the direct estimates to obtain an overall impact estimate to the specified industries. The IMPLAN multiplier methodology also gives multipliers for indirect and induced impacts that are able to be calculated separately from the total impact at the regional level. The use of the IMPLAN multiplier methodology created multiplier ranges for the total impact on output between 1.63 to 2.29 and a total employment multiplier range of 12.51 to 24.94 per $\$ 1$ million in direct spending with industry specific multipliers.

\section{SPORTING EVENTS IN LANE COUNTY}

Travel Lane County assists sporting events with finding appropriate venues to meet their needs, promoting the event, and even helping to find rooms for the competitors and their families to stay in. Travel Lane County has collected statistics on the events that they have helped with, including the number of out-of-town visitors broken down by event. For this paper, the authors used the most recent data for a full year's impact from 2013. Table 1 summarizes the visitor data:

\section{Table 1: Visitor Breakdown by Type of Visit}

\begin{tabular}{l|l} 
Sum of Show Attendees & $\mathbf{2 0 5 , 5 9 7}$ \\
\hline Sum of Hotel Attendees & 60,568 \\
\hline Sum of Day Attendees & 145,029 \\
\hline Adjusted Hotel Attendees & 139,630 \\
\hline Adjusted Day Attendees & 293,067
\end{tabular}

Sum of Show Attendees is the total number of individual spectators who visited sporting events in Lane County each year. Sum of Hotel Attendees is the number of individuals who stayed in a hotel during their visit, and Sum of Day Attendees is the number of individuals who did not stay in a hotel during their visit. As several events last more than one day, it is necessary to account for the fact that visitors will be spending money each day they are here. Adjusted Hotel Attendees takes into account multiple-day hotel stays. Similarly, Adjusted Day Attendees takes into account day visitors who do not stay in a hotel during multiple day sporting events.

Day Attendees include everyone who attended a sporting event without staying in a hotel. Unfortunately, there was no available data whether or not these individuals chose not to stay in a hotel because they live in Lane County already, or because they chose to return to their home outside of Lane County. As mentioned above, money from outside the county is the primary driver of additional growth. Money spent by the residents of the county is most likely displaced from other recreational spending within the city. Further complicating the analysis, the number of outof-town visitors depends on the specific event. With individual high school sporting events, around half the players in the game are from out-of-town. With larger events, such as regional championships, or the Olympic Trials, that number is likely to be considerably higher. To account for the lack of this data, we have prepared a range of estimates from which to consider. In Table 2 we assumed that 25\%, 33\%, and 50\% of day visitors are from out-of-town. 
Table 2: Estimated Number of Out-of-Town Day Attendees

\begin{tabular}{l|l|l} 
Percentage & Estimated Sum of Attendees & Estimated Adjusted Attendees \\
\hline $25 \%$ & 36,257 & 73,267 \\
\hline $33 \%$ & 47,860 & 96,712 \\
\hline $55 \%$ & 72,515 & 146,534
\end{tabular}

The variety of venues and events is crucial to the overall sporting culture in Eugene. In order to understand why this is the case, we turn to a study from Dean Runyan Associates, a Portland based economic consulting firm who has compiled county-specific traveler spending and impact information, detailed in Table 3.

Table 3: Dean Runyan Associates Estimates of Aggregate Visitor Spending

\begin{tabular}{l|l} 
Industry Spending & Direct Impact (in millions of dollars) \\
\hline Accommodation \& Food Services & 1422.1 \\
\hline Professional Services & 0 \\
\hline Transportation & 344.5 \\
\hline Arts, Entertainment, \& Recreation & 290.9 \\
\hline Government & 0 \\
\hline Retail Trade & 233 \\
\hline Finance, Ins., \& Real Estate & 0 \\
\hline Other Services & 0 \\
\hline Mining \& Manufacturing & 0 \\
\hline Agriculture and Food & 0 \\
\hline Processing (Construction) & 0 \\
\hline Total Spending & $\mathbf{2 2 9 0 . 5}$
\end{tabular}

As Table 3 shows, most traveler spending occurs in the services sectors, particularly food services, and hotels. Service industries tend to have flexible staffing, so increased customer needs during single events can be satisfied by providing current employees with extra hours. While this does provide the currently employed with more income, there may be no need for businesses to add additional jobs. It is the overall sporting culture in Eugene that contributes to persistent job creation. Therefore, in this study we do not consider the impact of any single sporting event; instead, we focus on the aggregate impact of sporting culture in Eugene.

\section{ESTIMATED IMPACT-TRAVEL LANE COUNTY/DEAN RUNYAN ASSOCIATES}

The data provided by Travel Lane County provides the primary estimates of the overall direct economic impact of sporting events. To determine the indirect impact, we use the RIMS II multipliers, in Table 4 . 
Table 4: RIMS II Multipliers for Relevant Industries

\begin{tabular}{l|l|l|l} 
& \multicolumn{3}{l}{ Multipliers } \\
\hline & Output & Earnings & Employment \\
\hline Lodging & 1.6459 & 0.4979 & 19.4989 \\
\hline Retail Shopping & 1.6384 & 0.5278 & 20.1867 \\
\hline Food \& Beverage & 1.7249 & 0.5255 & 24.5683 \\
\hline Private Auto Expenses & 1.6700 & 0.5186 & 15.3333 \\
\hline Rental Car Expenses & 1.6346 & 0.4033 & 8.6956 \\
\hline Airfare & 1.6695 & 0.5452 & 13.2854 \\
\hline Other & 1.6627 & 0.4192 & 18.4762
\end{tabular}

For example, every dollar spent by an out-of-town guest for lodging, once it has circulated fully through the economy, actually generates $\$ 1.6459$ in total economic activity and $\$ 0.4979$ in earnings for local workers. The employment multiplier estimates that 19.4989 jobs are created per $\$ 1,000,000$ aggregate spending on lodging. As stated above, it is important to remember that the jobs multiplier relies on aggregate visitor spending, because service industry employers are able to offer extra hours to current employees easily to accommodate one-time events, without actually creating new jobs. For example, the Olympic Trials at Hayward Field last for nine days, every four years. Businesses are very unlikely to take on the substantial cost of hiring and training new staff just for nine days of events, only to lay off those new staffers as demand returns to normal levels. Dean Runyan Associates estimates that, in Lane County specifically, it requires $\$ 69,680$ of aggregate visitor spending to create one job, or a multiplier of 14.351 jobs per million dollars in aggregate visitor spending.

As noted above, the available data did not differentiate between day attendees who lived in Lane County, and those attendees who live outside the county. To fully account for this, the report will first estimate the impact from only hotel attendees, and then estimate the impact of day attendees using the proportions from above.

The primary difficulty lies in determining how much the average out-of-town visitor spends. This report uses two different spending habits for tourists to estimate the economic impact. The first spending estimates, listed in Table 5, use the spending estimate of $\$ 166 /$ day for hotel attendees, proportioned into industry-specific spending habits using the data from Dean Runyan Associates. 
Table 5: Estimates of Aggregate Spending by Spectators Staying Overnight

\begin{tabular}{l|l|l} 
Industry & Percentage of Total Spending & Direct Spending Per Industry \\
\hline Accommodation and Food Services & $62.11 \%$ & $\$ 14,396,216$ \\
\hline Transportation & $15.05 \%$ & $\$ 3,488,376$ \\
\hline Arts, Entertainment, and Recreation & $12.67 \%$ & $\$ 2,936,726$ \\
\hline Retail Trade & $10.18 \%$ & $\$ 2,359,579$
\end{tabular}

There is one final complication to address. For retail sales (including gasoline sales), only a portion of the spending remains in the local economy to produce an impact. The remainder must pass from the seller to the producer. This can be in the form of profit, retained earnings, or dividends issued to owners. The amount that remains with the local retailer is known as the margin. The use of the margin is a standard accounting convention allows the true impact of retail sales alone to be determined, instead of conflating the sales and production of retail goods together. In other words, without a margin, the impact of the creation of retail goods would be included in the sales of retail goods, greatly overstating the true impact of retail sales ${ }^{1}$. The margins, also provided by Dean Runyan Associates, and the final direct impact of overnight visitors, are listed in table 6.

Table 6: Estimates of Direct Spending Totals by Spectators Staying Overnight

\begin{tabular}{l|l|l|l} 
Industry & Estimated Spending Per Industry & Margin & Direct Spending \\
\hline Accommodation and Food Services & $\$ 14,396,216$ & 1 & $\$ 14,396,216$ \\
\hline Transportation & $\$ 3,488,376$ & 0.17 & $\$ 593,024$ \\
\hline Arts, Entertainment, and Recreation & $\$ 2,936,726$ & 1 & $\$ 2,936,726$ \\
\hline Retail Trade & $\$ 2,359,579$ & 0.5 & $\$ 1,179,790$
\end{tabular}

With the industry specific spending, the appropriate industry specific multiplier is applied to determine the overall impact ${ }^{2}$, and the total direct impact is recorded in Table 7.

\section{Table 7: Total Direct Impact of Out-of-Town Visitors For Sporting Events - Dean Runyan Associates Spending Estimates}

\begin{tabular}{l|l|l|l|l} 
Industry & Direct Spending & Output & Earnings & Employment \\
\hline Accommodation and Food Services & $\$ 14,396,216$ & $\$ 23,733,602$ & $\$ 7,075,740$ & 279 \\
\hline Transportation & $\$ 593,024$ & $\$ 1,048,051$ & $\$ 325,689$ & 11 \\
\hline Arts, Entertainment, and Recreation & $\$ 2,936,726$ & $\$ 5,001,538$ & $\$ 1,588,475$ & 63 \\
\hline Retail Trade & $\$ 1,179,790$ & $\$ 1,932,732$ & $\$ 620,569$ & 23 \\
\hline Total & $\mathbf{\$ 1 9 , 1 0 5 , 7 5 6}$ & $\mathbf{\$ 3 1 , 7 1 5 , 9 2 3}$ & $\mathbf{\$ 9 , 6 1 0 , 4 7 3}$ & $\mathbf{3 7 6}$
\end{tabular}

\footnotetext{
${ }^{1}$ More information on margins, and why they are necessary for economic impact studies, can be found in the BEA RIMS II User's Guide.

${ }^{2}$ In the case where the industry groupings used by Dean Runyan Associates covered two industries as defined by the BEA, the smaller of the two RIMS II multipliers was used.
} 
These numbers apply to the "average traveler" into Lane County, which means they do not take into account the unique spending habits of sporting spectators. People in town for recreation are here in order to experience something in the town, which typically involves spending money at local businesses. People in town on business, or those simply staying the night passing through, are less likely to spend money, which means these numbers likely underestimate the true overall impact.

As mentioned above, the data provided by Travel Lane County did not differentiate between day visitors who live in Lane County and those who do not. In Table 8 we use the $25 \%$, 33\%, and $50 \%$ estimates of out-of-town day visitors to estimate the total aggregate direct spending.

Table 8: Direct Spending Estimates Based on Percentage of Day Visitors From Out-of-Town

\begin{tabular}{l|l|l|l} 
Industry & $\mathbf{2 5 \%}$ & $\mathbf{3 3 \%}$ & $\mathbf{5 0 \%}$ \\
\hline Accommodation and Food Services & $\$ 2,593,841$ & $\$ 3,423,870$ & $\$ 5,187,682$ \\
\hline Transportation & $\$ 106,848$ & $\$ 141,040$ & $\$ 213,696$ \\
\hline Arts, Entertainment, and Recreation & $\$ 529,125$ & $\$ 698,445$ & $\$ 1,058,250$ \\
\hline Retail Trade & $\$ 212,569$ & $\$ 280,591$ & $\$ 425,138$
\end{tabular}

Finally, using the multipliers from Table 4, we arrive at estimated final demand impact for each percentage estimate.

Table 9: Economic Impact Estimates for Varying Percentages of Out-of-Town Day Attendees

\begin{tabular}{l|l|l|l} 
Industry: 25\% & Output & Earnings & Employment \\
\hline Accommodation and Food Services & $\$ 4,276,206$ & $\$ 1,274,873$ & 50 \\
\hline Transportation & $\$ 188,833$ & $\$ 58,681$ & 2 \\
\hline Arts, Entertainment, and Recreation & $\$ 901,153$ & $\$ 286,204$ & 11 \\
\hline Retail Trade & $\$ 348,230$ & $\$ 111,811$ & 4 \\
\hline Total & $\mathbf{\$ 5 , 7 1 4 , 4 2 2}$ & $\mathbf{\$ 1 , 7 3 1 , 5 6 9}$ & $\mathbf{6 8}$
\end{tabular}

\begin{tabular}{l|l|l|l} 
Industry: 33\% & Output & Earnings & Employment \\
\hline Accommodation and Food Services & $\$ 5,644,592$ & $\$ 1,682,832$ & 66 \\
\hline Transportation & $\$ 249,259$ & $\$ 77,459$ & 3 \\
\hline Arts, Entertainment, and Recreation & $\$ 1,189,522$ & $\$ 377,789$ & 15 \\
\hline Retail Trade & $\$ 459,664$ & $\$ 147,591$ & 6 \\
\hline Total & $\mathbf{\$ 7 , 5 4 3 , 0 3 7}$ & $\mathbf{\$ 2 , 2 8 5 , 6 7 1}$ & $\mathbf{8 9}$
\end{tabular}




\begin{tabular}{l|l|l|l} 
Industry: 5o\% & Output & Earnings & Employment \\
\hline Accommodation and Food Services & $\$ 8,552,412$ & $\$ 2,549,745$ & 101 \\
\hline Transportation & $\$ 377,666$ & $\$ 117,362$ & 4 \\
\hline Arts, Entertainment, and Recreation & $\$ 1,802,306$ & $\$ 572,408$ & 23 \\
\hline Retail Trade & $\$ 696,460$ & $\$ 223,622$ & 8 \\
\hline Total & $\mathbf{\$ 1 1 , 4 2 8 , 8 4 4}$ & $\mathbf{\$ 3 , 4 6 3 , 1 3 8}$ & $\mathbf{1 3 6}$
\end{tabular}

In total, it is estimated:

- $\quad$ Between $\$ 37,430,345$ and $\$ 43,144,767$ generated in additional output;

- $\quad$ Between $\$ 11,342,042$ and $\$ 13,073,611$ in additional earning for local employees;

- $\quad$ Between 444 and 512 additional jobs created in 2013 to accommodate these visitors.

The second set of spending estimates is provided by Timothy Duy, PhD., a faculty member in the economics department at the University of Oregon. The numbers are taken from a survey of visitors to the Duck's athletic events, and so may more closely represent actual spending habits of sporting spectators in Lane County.

Table 10: Estimates of Individual Spending

\begin{tabular}{l|l|l|l} 
Industry & Oregon Visitor Day & Oregon Visitor Overnight & Out of State Visitor \\
\hline Lodging & $\$ 3.09$ & $\$ 41.08$ & $\$ 31.46$ \\
\hline Retail Shopping & $\$ 17.93$ & $\$ 23.55$ & $\$ 23.81$ \\
\hline Food and Beverage & $\$ 25.48$ & $\$ 33.49$ & $\$ 32.59$ \\
\hline Private Auto Expenses & $\$ 27.58$ & $\$ 27.16$ & $\$ 19.31$ \\
\hline Rental Car Expenses & $\$ 0.77$ & $\$ 0.34$ & $\$ 5.66$ \\
\hline Airfare & $\$ 0.07$ & $\$ 1.75$ & $\$ 37.20$ \\
\hline Other & $\$ 6.49$ & $\$ 7.43$ & $\$ 8.60$ \\
\hline Total & $\mathbf{\$ 8 1 . 4 1}$ & $\mathbf{\$ 1 3 4 . 8 0}$ & $\mathbf{\$ 1 5 8 . 6 3}$
\end{tabular}

As these are individual spending numbers they must be adjusted for aggregate spending in order to determine the full aggregate spending per industry, per year. As before, these numbers are estimates of the total direct impact. As such, a margin is needed to determine an accurate economic impact. Duy provides these margins in "The Economic Impact of the University of Oregon Athletics Department.” Table 11 provides the initial estimated spending numbers. 
Table 11: Aggregate Spending by Overnight Visitors

\begin{tabular}{l|l|l|l} 
Industry & Estimated Output & Margin & Direct Spending \\
\hline Lodging & $\$ 5,736,000$ & 1 & $\$ 5,736,000$ \\
\hline Retail Shopping & $\$ 3,288,287$ & 0.5 & $\$ 1,644,143$ \\
\hline Food and Beverage & $\$ 4,676,209$ & 1 & $\$ 4,676,209$ \\
\hline Private Auto Expenses & $\$ 3,792,351$ & 0.5 & $\$ 1,896,175$ \\
\hline Rental Car Expenses & $\$ 47,474$ & 1 & $\$ 47,474$ \\
\hline Airfare & $\$ 244,353$ & 1 & $\$ 244,353$ \\
\hline Other & $\$ 1,037,451$ & 0.5 & $\$ 518,725$ \\
\hline Total & $\mathbf{\$ 1 8 , 8 2 2 , 1 2 4}$ & & $\mathbf{\$ 1 4 , 7 6 3 , 0 8 0}$
\end{tabular}

As above, the industry-appropriate multipliers are used to determine the overall economic output of overnight visitors.

Table 12: Estimated Final Demand Impact by Overnight Visitors

\begin{tabular}{l|l|l|l} 
Industry & Output & Earnings & Employment \\
\hline Lodging & $\$ 9,440,883$ & $\$ 2,855,955$ & 112 \\
\hline Retail Shopping & $\$ 2,693,764$ & $\$ 867,779$ & 33 \\
\hline Food and Beverage & $\$ 8,065,992$ & $\$ 2,457,348$ & 115 \\
\hline Private Auto Expenses & $\$ 3,166,613$ & $\$ 983,357$ & 29 \\
\hline Rental Car Expenses & $\$ 77,601$ & $\$ 19,146$ & 0 \\
\hline Airfare & $\$ 407,946$ & $\$ 133,221$ & 3 \\
\hline Other & $\$ 862,485$ & $\$ 217,450$ & 10 \\
\hline Total & $\mathbf{\$ 2 4 , 7 1 5 , 2 8 5}$ & $\mathbf{\$ 7 , 5 3 4 , 2 5 5}$ & $\mathbf{3 0 2}$
\end{tabular}

To determine the impact of day visitors, we again construct estimates of $25 \%, 33 \%$, and $50 \%$ of all day visitors being from out of the area. The direct spending estimates are given in table 13 .

Table 13: Estimated Direct Spending by Day Visitors - Varying Percentages

\begin{tabular}{l|l|l|l} 
Industry & $\mathbf{2 5 \%}$ & $\mathbf{3 3 \%}$ & $\mathbf{5 0 \%}$ \\
\hline Lodging & $\$ 226,394$ & $\$ 298,840$ & $\$ 452,789$ \\
\hline Retail Shopping & $\$ 656,836$ & $\$ 867,024$ & $\$ 1,313,673$ \\
\hline Food and Beverage & $\$ 1,866,837$ & $\$ 2,464,225$ & $\$ 3,733,674$ \\
\hline Private Auto Expenses & $\$ 1,010,348$ & $\$ 1,333,660$ & $\$ 2,020,697$ \\
\hline Rental Car Expenses & $\$ 56,415$ & $\$ 74,468$ & $\$ 112,831$ \\
\hline Airfare & $\$ 5,129$ & $\$ 6,770$ & $\$ 10,257$ \\
\hline Other & $\$ 237,751$ & $\$ 313,831$ & $\$ 475,501$ \\
\hline Total & $\mathbf{\$ 4 , 0 5 9 , 7 1 1}$ & $\mathbf{\$ 5 , 3 5 8 , 8 1 8}$ & $\mathbf{\$ 8 , 1 1 9 , 4 2 1}$
\end{tabular}


Multipliers are applied to determine the final, full economic impact of day visitors.

Table 14: Economic Impact Estimates for Varying Percentages of Day Visitors from Out of Lane County

\begin{tabular}{l|l|l|l} 
Industry: 25\% & Output & Earnings & Employment \\
\hline Lodging & $\$ 372,622$ & $\$ 112,722$ & 4 \\
\hline Retail Shopping & $\$ 1,076,161$ & $\$ 346,678$ & 13 \\
\hline Food and Beverage & $\$ 3,220,107$ & $\$ 981,023$ & 46 \\
\hline Private Auto Expenses & $\$ 1,687,282$ & $\$ 523,967$ & 15 \\
\hline Rental Car Expenses & $\$ 92,217$ & $\$ 22,752$ & 0 \\
\hline Airfare & $\$ 8,562$ & $\$ 2,796$ & 0 \\
\hline Other & $\$ 395,308$ & $\$ 99,665$ & 4 \\
\hline Total & $\mathbf{\$ 6 , 8 5 2 , 2 5 9}$ & $\mathbf{\$ 2 , 0 8 9 , 6 0 3}$ & $\mathbf{8 4}$
\end{tabular}

\begin{tabular}{l|l|l|l} 
Industry: 33\% & Output & Earnings & Employment \\
\hline Lodging & $\$ 491,861$ & $\$ 148,793$ & 6 \\
\hline Retail Shopping & $\$ 1,420,532$ & $\$ 457,615$ & 18 \\
\hline Food and Beverage & $\$ 4,250,541$ & $\$ 1,294,950$ & 61 \\
\hline Private Auto Expenses & $\$ 2,227,212$ & $\$ 691,636$ & 20 \\
\hline Rental Car Expenses & $\$ 121,726$ & $\$ 30,033$ & 1 \\
\hline Airfare & $\$ 11,302$ & $\$ 3,691$ & 0 \\
\hline Other & $\$ 521,806$ & $\$ 131,558$ & 6 \\
\hline Total & $\mathbf{\$ 9 , 0 4 4 , 9 8 1}$ & $\mathbf{\$ 2 , 7 5 8 , 2 7 6}$ & $\mathbf{1 1 1}$
\end{tabular}

\begin{tabular}{l|l|l|l} 
Industry: 50\% & Output & Earnings & Employment \\
\hline Lodging & $\$ 745,245$ & $\$ 225,443$ & 9 \\
\hline Retail Shopping & $\$ 2,152,322$ & $\$ 693,357$ & 27 \\
\hline Food and Beverage & $\$ 6,440,214$ & $\$ 1,962,045$ & 92 \\
\hline Private Auto Expenses & $\$ 3,374,564$ & $\$ 1,047,933$ & 31 \\
\hline Rental Car Expenses & $\$ 184,433$ & $\$ 45,505$ & 1 \\
\hline Airfare & $\$ 17,125$ & $\$ 5,592$ & 0 \\
\hline Other & $\$ 790,616$ & $\$ 199,330$ & 9 \\
\hline Total & $\mathbf{\$ 1 3 , 7 0 4 , 5 1 7}$ & $\mathbf{\$ 4 , 1 7 9 , 2 0 6}$ & $\mathbf{1 6 8}$
\end{tabular}

In total, it is estimated:

- $\quad$ Between $\$ 31,567,544$ and $\$ 38,419,803$ in additional output in Lane County;

- $\quad$ Between $\$ 9,623,858$ and $\$ 11,713,461$ in additional earning for employees in Lane County; 
- $\quad$ Between 386 and 470 additional jobs created.

\section{ESTIMATED IMPACT-OTHER LOCAL EVENTS}

In addition to the groups that Travel Lane County works with, Eugene hosts hundreds of other sporting events every year. To take these events into account, a survey was sent out to several sports facilities and organizations inquiring about their events. Unfortunately, many of these events involve youth athletics, which complicates the data collection process. Junction City Athletics (JCA), for example, hosts leagues for youth baseball, softball, soccer, and flag football. In addition, they host a series of girls' fast pitch tournaments every year, as well as renting out their 13-acre complex for another organization's fast pitch tournament. JCA is also a volunteerdriven organization and the leagues that participate in these tournaments are not necessarily affiliated with any one school. This means there simply is no money available for robust data collection. Similarly, the Eugene area high schools hold many youth sporting events, including tournaments and one-off games against visiting teams. The ticket takers and concession workers at these events are usually parents - again, meaning there is no formal, robust way to collect useful data.

In some cases, such as recreational sporting leagues for adults, there is no contact information available, as the teams and leagues are arranged in an ad hoc fashion, with simple email lists shared between members. There is no available data, yet these players enjoy meals together after games, and in some cases pool money to rent fields and pay fees associated with their sports. Keeping the difficulties in managing this data in mind, we applied a very conservative methodology to estimate the impact.

JCA, as mentioned above, has rougher estimates of overall participation. Mark Steinmetz, one of the sports directors for JCA, provided us with some of those estimates. According to Mr. Steinmetz, JCA hosts six major fast pitch tournaments every summer. On average, thirty teams attend with twelve players per team. As these are high school events, many family members visit the area along with the athletes, so Mr. Steinmetz estimates four visitors per family. Once coaches and staff are included, JCA estimates 60 individuals per team, per tournament attend each of these three-day events. Finally, Mr. Steinmetz informed us that most of the teams who attend these events are from out of the area. We estimated that $80 \%$ of the attendees were from outside Lane County.

Lane Community College (LCC) hosts several events during the year, including youth soccer, high school baseball, and several events for the Oregon Schools Athletics Association, among others. Brent Ellison, Director of Student Recreation and Special Events for LCC, provided us with data for total participants in the events LCC hosted during 2013, and, for certain events, estimates of total spectators. These numbers were used to estimate total attendance. We did not include an economic impact from the practices, as they obviously would only include local families. We also did not include an economic impact from normal season play, focusing instead on tournaments, meets, and other special events. This is because normal season play includes games played at home and away. While money does enter the local economy as out-of-town 
attendees spend money during their visit, money also leaves the local economy as local families take their money out-of-town. For the special events, LCC unfortunately does not track where the athletes and spectators are coming from. Many of these events are tournaments/meets, so we again assume $80 \%$ of the attendees were from out-of-town. The attendees are presented in Table 15 .

\section{Table 15: Estimated Visitors from Secondary Data}

\begin{tabular}{l|l|l} 
& LCC & JCA \\
\hline Sum of Participants & 6,230 & 2,160 \\
\hline Sum of Spectators & 22,678 & 8,640 \\
\hline Sum of Adjusted Hotel Attendees & 77,800 & 22,896 \\
\hline Sum of Adjusted Day Attendees & 19,450 & 5,184
\end{tabular}

As above, the fact that several events (including all of the JCA events) were held over the course of several days was accounted for, by using Sum of Total Hotel-Day Attendees to account for individuals who stayed several days in a local hotel, and Sum of Day Attendees used to account for individuals who spent the night at home, returning each day for the event.

With these estimates, we first use the spending estimates from Travel Lane County, with the Dean Runyan Associates industry proportions. Then, we break down the spending and apply the appropriate multipliers, as above.

Table 16: Estimated Economic Impact of LCC and JCA events - Dean Runyan Associates Spending Estimates

\begin{tabular}{l|l|l|l|l|l|l} 
Industry & $\begin{array}{l}\text { Estimated } \\
\text { Spending } \\
\text { per Industry }\end{array}$ & Margin & $\begin{array}{l}\text { Direct } \\
\text { Spending }\end{array}$ & Output & Earnings & Employment \\
\hline $\begin{array}{l}\text { Accommodation and } \\
\text { Food Services }\end{array}$ & $\$ 5,791,705$ & 1.00 & $\$ 5,791,705$ & $\$ 9,548,205$ & $\$ 2,846,623$ & 112 \\
\hline Transportation & $\$ 1,403,400$ & 0.17 & $\$ 238,578$ & $\$ 421,639$ & $\$ 131,027$ & 4 \\
\hline $\begin{array}{l}\text { Arts, Entertainment, } \\
\text { and Recreation }\end{array}$ & $\$ 1,181,467$ & 1.00 & $\$ 1,181,467$ & $\$ 2,012,156$ & $\$ 639,055$ & 25 \\
\hline Retail Trade & $\$ 949,276$ & 0.50 & $\$ 474,638$ & $\$ 777,552$ & $\$ 249,660$ & 9 \\
\hline Total & & & & $\mathbf{\$ 1 2 , 7 5 9 , 5 5 3}$ & $\mathbf{\$ 3}, \mathbf{8 6 6 , 3 6 5}$ & $\mathbf{1 5 1}$
\end{tabular}

Using the spending estimates provided by Professor Duy, we construct the estimates in Table 17. 
Table 17: Estimated Economic Impact of LCC and JCA Events -Duy Spending Estimates

\begin{tabular}{|c|c|c|c|c|c|c|}
\hline & \begin{tabular}{|l|} 
Estimated \\
Spending
\end{tabular} & Margin & $\begin{array}{l}\text { Direct } \\
\text { Spending }\end{array}$ & Output & Earnings & Employment \\
\hline Lodging & $\$ 2,170,644$ & 1.00 & $\$ 2,170,644$ & $\$ 3,572,662$ & $\$ 1,080,763$ & 42 \\
\hline Retail Shopping & $\$ 1,445,317$ & 0.50 & $\$ 722,658$ & $\$ 1,184,003$ & $\$ 381,419$ & 15 \\
\hline Food and Beverage & $\$ 2,055,134$ & 1.00 & $\$ 2,055,134$ & $\$ 3,544,901$ & $\$ 1,079,973$ & 50 \\
\hline Private Auto Expenses & $\$ 1,752,698$ & 0.50 & $\$ 876,349$ & $\$ 1,463,502$ & $\$ 454,474$ & 13 \\
\hline Rental Car Expenses & $\$ 27,223$ & 1.00 & $\$ 27,223$ & $\$ 44,499$ & $\$ 10,979$ & 0 \\
\hline Airfare & $\$ 91,703$ & 1.00 & $\$ 91,703$ & $\$ 153,097$ & $\$ 49,996$ & 1 \\
\hline Other & $\$ 466,356$ & 0.50 & $\$ 233,178$ & $\$ 387,705$ & $\$ 97,748$ & 4 \\
\hline Total & & & $\$ 6,176,889$ & $\$ 10,350,371$ & $\$ 3,155,354$ & 127 \\
\hline
\end{tabular}

Combined, these two organizations provided sports facilities for an additional 8,390 athletes and 31,318 spectators to Lane County in 2013. These spectators generated between $\$ 6.2$ and $\$ 12.7$ million in local spending, $\$ 3.2$ to $\$ 3.8$ million in additional earnings for local workers and between 127 and 151 additional jobs in Lane County. This all further highlights the importance of having a diverse portfolio of sporting events in Lane County.

It is important to note that these are just two organizations that host these events. There are many more organizations that had no data at all available, yet clearly provide a large economic impact to the area.

\section{ESTIMATED IMPACT-THE UNIVERSITY OF OREGON}

No study of the impact of sporting events in Lane County would be complete without taking into account the impact of the University of Oregon's athletic program: the Oregon Ducks. As mentioned above, the impact of the Ducks is not just limited to the university's formal athletic program. To detail the economic impact, we again draw on a study from Duy, for the 2011-2012 fiscal year. As in this report, the economic impact is estimated using spending estimates from both Dean Runyan Associates, given here in Table 12, and Duy's work with the Duck athletic department (Duy, Economic Impact of the University of Oregon: A Comprehensive Revision), given here in Table $13^{3}$.

3 Note that both of these studies are measuring economic impact across the fiscal years. The rest of this study measures impact across calendar years. 
Table 18: Tourist Spending - FY 2012: Dean Runyan Associates

\begin{tabular}{l|l|l|l|l} 
& Direct Expenditures & Output & Earnings & Jobs \\
\hline Food Service & $6,784,344$ & $14,011,026$ & $4,055,002$ & 177 \\
\hline Accommodations & $4,085,738$ & $7,703,660$ & $2,263,499$ & 85 \\
\hline Retail Sales & $\mathbf{1 , 8 4 3 , 5 9 0}$ & $3,470,005$ & $1,067,439$ & 39 \\
\hline Local Tran. \& Gas & 575,602 & $1,083,397$ & 333,273 & 12 \\
\hline Arts, Ent. \& Rec. & $3,127,355$ & $6,082,706$ & $1,881,730$ & 9 \\
\hline Food Stores & $\mathbf{6 4 5 , 8 1 6}$ & $\mathbf{1 , 2 1 5 , 5 5 4}$ & 373,927 & 14 \\
\hline Visitor Air Tran. & $\mathbf{1 , 6 8 9 , 7 8 1}$ & $3,088,750$ & 769,188 & 19 \\
\hline Total & $\mathbf{\$ 1 8 , 7 5 2 , 2 2 6}$ & $\mathbf{\$ 3 6 , 6 5 5 , 0 9 8}$ & $\mathbf{\$ 1 0 , 7 4 4 , 0 5 8}$ & $\mathbf{3 5 5}$
\end{tabular}

Table 19: Tourist Spending - FY 2012: Duy

\begin{tabular}{l|l|l|l|l} 
& Direct Expenditures & Output & Earnings & Jobs \\
\hline Accommodations & $6,398,712$ & $12,064,772$ & $3,544,887$ & 133 \\
\hline Retail Sales & $\mathbf{2 , 4 0 8 , 1 5 7}$ & $4,532,632$ & $1,394,323$ & 51 \\
\hline Food Service & $\mathbf{6 , 6 2 8 , 5 4 5}$ & $13,689,272$ & $3,961,882$ & 173 \\
\hline Local Tran. \& Gas & $1,953,024$ & $3,675,982$ & $1,130,801$ & 42 \\
\hline Rental Car & $\mathbf{1 , 1 5 1 , 1 9 9}$ & $\mathbf{2 , 1 6 6 , 4 4 1}$ & 515,852 & 11 \\
\hline Visitor Air Tran. & $\mathbf{7 , 5 6 6 , 1 8 2}$ & $\mathbf{1 3 , 8 3 0 , 2 2 5}$ & $3,444,126$ & 85 \\
\hline Other & $\mathbf{8 6 9 , 8 0 9}$ & $\mathbf{1 , 6 3 7 , 1 5 4}$ & 503,619 & 18 \\
\hline Total & $\mathbf{\$ 2 6 , 9 7 5 , 6 2 8}$ & $\mathbf{\$ 5 1 , 5 9 6 , 4 7 8}$ & $\mathbf{\$ 1 4 , 4 9 5 , 4 9 0}$ & $\mathbf{5 1 3}$
\end{tabular}

It must be noted that the Olympic Trials were held in 2012, and as such, these numbers are likely higher than they would be in years without those trials.

\section{UNQUANTIFIABLE BENEFITS}

The impact and influence of sporting events goes beyond the measure of dollars spent in an economy. These sporting events produce many unquantifiable benefits for their communities.

Local teams help create an atmosphere of team spirit and local excitement. This creates a sense of community that is hard to find anywhere outside of sports. Observe the Timbers Army, the supporters group of the Portland Timbers, or the parking lot of Autzen Stadium on any given game day. This attention and community atmosphere creates additional awareness for local schools and programs that could lead to educational contributions, facility improvements, and increased enrollment. The sense of community even helps to inspire public volunteerism, leading to additional opportunities for members of a community to interact and work together for common goals.

Media coverage, particularly for events at the regional, state, and national level, provides free exposure for Lane County, alerting a wider audience to the opportunities in the area. Media 
exposure can lead to increases in tourism, and even more interest from the state and national community in holding more sporting events in Lane County, a virtuous cycle.

Finally, as this paper demonstrates, people enjoy watching sporting events in person. Sports are a strong enough cultural institution that people will set aside time and money specifically to spend watching sports. With several major franchises nearby - the Portland Blazers, the Portland Timbers, and the Oregon State University Beavers - there are ample opportunities for residents of Lane County to leave the area to enjoy sports. Part of the methodology of economic impact studies includes the assumption that spending by local attendees involves circulation of existing money, not adding money to contribute to overall growth. If the presence of local sports does provide a means for local residents to spend their money in the community, then that money should be counted as money that the local community would otherwise not have access to. This is particularly true in the case of high school regional and state level tournaments. These tournaments will happen somewhere. If they do not take place in Lane County, then parents of Lane County high school athletes will leave town and go spend their money elsewhere. This unmeasurable "anchoring effect" means that the study necessarily understates the overall economic impact of local sporting events.

\section{SPORTING INFRASTRUCTURE}

When arguing for additional spending on sporting infrastructure, the public is concerned with any estimated economic impact studies that seek to justify the public expense - and rightly so. These studies are commissioned by organizations who are seeking out public money to expand their facilities, and have every incentive to make broad assumptions about spending habits, occupancy, and cost, in order to justify the spending. This unfortunately means that the public is skeptical about any economic work seeking to justify the public spending, regardless of the level of care that went into the study.

To combat this negative public sentiment, keep in mind the value of a diverse sporting culture. If a facility adds value to the community not only for the one-off events that are hosted there, but for a broad array of events open to the public, then the focus shifts from a simple return-oninvestment calculation to a much broader focus on overall benefits to the community, including the unquantifiable benefits discussed above.

Consider the recently completed WJ Skate Park and Urban Plaza. As the largest covered outdoor skate park in the nation, it is often the site of skating tournaments. However, when there are no scheduled tournaments, the all-ages park is open to the public for free skating, or for rentals for celebrations or smaller competitions. The measureable economic impact is bolstered by the community impact the park generates, adding considerable value to Eugene.

Compare this impact with venues such as Autzen Stadium, or Matthew Knight Arena. These venues, while still very important to the area, are only useful to the community for the duration of a scheduled appointment. Outside of football games in Autzen, or basketball games and the occasional concert in Matthew Knight, the venues sit empty, adding no real value to the area. Hayward Field, on the other hand, while primarily a single-event space, is widely used by such a 
diverse number of organizations that even without being routinely available to the community it produces consistent economic benefits.

\section{FUTURE WORK}

The primary issue with this report is the lack of data from events not covered by Travel Lane County. These organizations simply lack the funding and manpower to accurately measure the number of visitors. It becomes very difficult to draw robust conclusions regarding the overall economic impact of these events, though there clearly is an impact. Future work on this project should therefore entail working with the other local sporting groups, including the JCA, the Eugene School District, Oregon Horse Center, and other groups, in order to allow for future researchers to more accurately determine how many people these diverse groups are bringing into Eugene.

By allying with other groups, there are two benefits beyond better understanding of the economic impact of sporting events. First, communication with other groups in the sporting industry allows for a greater ability to work with these groups to further encourage growth in the existing sporting culture, and all the benefits that come with it. Second, by allying with groups, and helping those groups develop the means to track attendance, the incredibly time consuming process of sending individual people to individual events to try and track attendance can be avoided entirely. With over 200,000 visitors to Lane County each year, it is important to maximize the return on effort when measuring attendance. Having attendance accurately measured at Willamalane Center would provide a far greater measure of impact than trying to send individual people to each individual event Willamalane hosts.

There are also assumptions about spending habits that should be examined. Lacrosse players, horse riders, and individuals who participate in yachting events possibly have different spending habits than families in town for a high school football game, or a youth basketball event. The most robust studies found used formal survey methods sent out to visitors to the events to determine the specific spending habits of those visitors. The typical visitor to the two tournaments in the Traverse City study had a median income of $\$ 124,000$, compared to the median income of the typical Michigan visitor to Traverse City of only $\$ 67,000$. Likewise, it is likely that athletes, media, and other individuals who come to Eugene for the Olympic Trials have very different spending habits than the parents who come to town to watch their daughter compete in her high school tournament. Duy's survey estimates that overnight visitors to the Duck football games spend, on average, $\$ 138$ per day. Travel Lane County estimates the typical overnight visitor to Lane County spends $\$ 166$ per day. With over 200,000 visitors to town for sporting events, even $\$ 30$ difference between the spending estimates produces a considerably different impact. Surveys of the attendees of individual events would provide a better understanding of these differences, and thus a more accurate estimate of the actual impact.

Finally, there are assumptions about how many people are coming to town for these events, athletes and spectators that merits closer examination. Much of Oregon's population is concentrated along the I-5 corridor, making for relatively easy access to Eugene. Better 
determination of how many of those attendees are staying overnight, versus visiting just for the day, would allow better estimates of their economic impact. As with spending habits, a survey handed out at individual events to collect this data would likely be the best way to collect this data.

\section{REFERENCES}

Baade, R. A., Baumann, R., \& Matheson, V. A. (2007). Big Men on Campus: Estimating the Economic Impact of College Sports on Local Economies. Regional Studies, 45(3), 371-380.

Beyers, William B. (n.d.). Economic Impact of the Husky Athletic Program on the Washington Economy.

Bureau of Economic Analysis - U.S. Department of Commerce. (n.d.). RIMS II User's Guide

Center for Business and Economic Research - Sam M. Walton College of Business, (2012). University of Arkansas Athletic Economic Impact.

Connaughton, J. E., \& Swartz, C. (2014). The Economic Impact Of Sports And Sporting Events On The Charlotte Metropolitan Statistical Area (MSA) Economy. Journal of Business \& Economics Research , 12(3), 215-230.

Crompton, John L. (1995). Economic Impact Analysis of Sports Facilities and Events: Eleven Sources of Misapplication. Journal of Sport Management, 9, 14-35.

Dean Runyan Associates. (2014) Oregon Travel Impacts, 1991-2013p.

Dixon, Anthony W., Henry, Mark, Martinez, \& J. Michael. (2013) Assessing the Economic Impact of Sport Tourists' Expenditures Related to a University's Baseball Season Attendance. Journal of Issues in Intercollegiate Athletics, 6, 69-113.

Duy, Timothy A. (2012) The Economic Impact of the University of Oregon Athletic Department.

The Economic Impact of the University of Oregon: A Comprehensive Revision. (n.d.).

Rosentraub, Mark S., Swindell, David. (2009). Doing Better: Sports, Economic Impact Analysis, and Schools of Public Policy and Administration. Journal of Public Affairs Education,14(2), 219-242.

Smith, Sherwood B., Trisdale, Ann. (2012). Game on! The Impact of Youth Sports on a Regional Economy.

Thompson, E. (2005). The Economic Impact of the University of Nebraska-Lincoln Athletic Department. Bureau of Business Research Publications, 15.

\section{APPENDIX A: RIMS II MODEL ASSUMPTIONS}

1) Backward linkages - In a backward-linkage model, an increase in demand for output results in an increase in the demand for inputs. RIMS II is a backward-linkage model. 
2) Fixed purchase patterns - Input-Output models use an assumption that specific industries do not change the relative mixture of the inputs used to produce output. In Input-Output models, it is also assumed that there are constant returns to scale, where if the industry doubles its inputs, it will produce double output. Without this assumption, using the model's multipliers may inflate the impact estimates due to industries that hire many part-time or seasonal workers. These industries can simply extend the staff's hours rather than hiring as many workers as the model assumes.

3) Industry Homogeneity - Input-Output models assume that all businesses within an industry use the same production process. If the production process of the business initially affected by a change in economic activity is not consistent with the production process of the industry in the national Input-Output accounts, using the RIMS II multipliers will yield inaccurate impact estimates.

4) No Supply Constraints - Input-Output models are commonly referred to as "fixed price" models because they assume that there are no price adjustments in response to supply constraints. With this we can assume that if a new business opens up within an industry, that business can hire new workers at the existing wage rate.

5) Local Supply Conditions - RIMS II is based on national Input-Output relationships that are adjusted to account for local supply conditions. These adjustments account for the fact that local industries often do not supply all of the intermediate inputs needed to produce the region's output. Industries must purchase some intermediate inputs from suppliers outside the region. These purchases are often called leakages because they represent money that no longer circulates in the local economy. RIMS II accounts for these leakages by considering each industry's concentration in the region relative to its concentration in the nation.

6) No Regional Feedback - RIMS II is a single region Input-Output model and it ignores any feedback that may exist among regions. Economic services for projects between two regions will not be accounted for using multipliers to estimate impacts.

7) No Time Dimension - The length of time that it takes for the total impact of an initial change in economic activity to be completely realized is unclear because time is not explicitly included in Input-Output models. The initial change in economic activity should be permanent, or at least persistent enough to fully work through the economy. 